\title{
PRINCIPAL COMPONENT ANALYSIS OF SOME PARAMETERS USED FOR LYCOPENE EXTRACTION FROM TOMATOES
}

\author{
V. Barbu, C. Neagu* and M. Dragan \\ Food Science and Engineering Faculty, Dunarea de Jos University, 111 Domneasca Street, Galati. Romania
}

(Received: 4 June 2014; accepted: 7 November 2014)

The present research is on the study of lycopene extraction from different raw and processed tomatoes, using traditional extraction methods with several solvents. The influences of the temperature and the light exposure were taken into consideration. The best extraction lycopene levels were obtained when chloroform:methanol mixture was used as solvent, followed by the hexane:acetone mixture and ethanol $95 \%$. The lycopene is better extracted at room temperature compared with refrigeration and freezing temperatures. Lyophilized tomatoes contained the highest amount of lycopene $(14.11 \mathrm{mg} / 100 \mathrm{~g})$, followed by dried tomatoes with $6.01 \mathrm{mg} / 100 \mathrm{~g}$, tomato juice with 11.38 $\mathrm{mg} / 100 \mathrm{~g}$, and the fresh tomatoes with $4.13 \mathrm{mg} / 100 \mathrm{~g}$.

Keywords: tomato, PCA, lycopene, solvent

The European Authority for Food Safety (EFSA) has recently focused on lycopene, considering it as one of the most important vegetal pigments with a huge practical potential, both in biotechnology and industry.

Detailed studies were carried out on lycopene extracted from tomatoes, as well as on lycopene produced by the fungus Blakeslea trispora, both compounds being safe for human consumption, although the fungal form showed a higher pigmentation power than the vegetable form. The use of lycopene from microbiological sources was certified only in 2004. Fungal lycopene was thus recognised as a safe food colouring with similar characteristics and uses as the lycopene extracted from tomatoes (Aguilar et al., 2008). Out of all vegetables, tomatoes contain the highest amount of lycopene $\left(46 \mu \mathrm{g} \mathrm{g}^{-1}\right)$, but lower amounts are also found in red beans, chilli peppers, green peppers, etc. The lycopene in tomato paste is four times more bioactive than in fresh tomatoes, and that is why tomato paste is often preferred as a lycopene source (RAO \& RAO, 2007; KHAN et al., 2008). The gac fruit (Momordica cochinchinensis Spreng.) has the highest lycopene content (2000-2300 $\left.\mu \mathrm{g} \mathrm{g}^{-1}\right)$ of all the known fruit and vegetables (70 times more than tomatoes), but due to its limited availability (it is only found in South-East Asia) its consumption is very low. The gac is a promising commercial source of lycopene, both in the extraction and in the purification process (ISHIDA et al., 2004).

The red watermelon ( $72 \mu \mathrm{g}$ lycopene/g) and guava ( $54 \mu \mathrm{g}$ lycopene/g), although very different in comparison to the gac fruit concerning the lycopene content, are to be noted due to their high accessibility in comparison to the other fruit, such as: pink grapefruit, papaya, apricots, nectarines, underbrush, rose hips, etc.

The earliest lycopene isolation procedure was recorded in 1910, but its molecular structure was only determined in 1931. It is known that structurally lycopene is a tetraterpene made up of 8 isoprene units, consisting almost entirely of carbon and hydrogen. Being made

\footnotetext{
* To whom correspondence should be addressed. Phone: +40-745-914376; e-mail: camelia.neagu@ugal.ro
} 
of a long chain of conjugated double bonds, with two open ring ends, lycopene has the longest structure of all carotenoids. The 11 conjugated double bonds of the lycopene structure yield its red colour and are responsible for its antioxidant activity (Grossman et al., 2004).

Lycopene is found in most foods in its natural all-trans form, and the lycopene molecule in this case is long and straight, constrained by its system of 11 conjugated double bonds (CRONIn, 2000; BoIleAu et al., 2002). When exposed to light or thermal energy, lycopene may undergo isomerisation, yielding cis-isomers. The isomers have distinct stabilities due to their molecular energy (the descending order of their stability degree is: 5-cis $\geq$ all-trans $\geq 9$-cis $\geq$ 13-cis $>15$-cis $>7$-cis $>11$-cis), but their individual biological properties have yet to be studied (CHASSE et al., 2001).

Due to its intense colour and lack of toxicity, lycopene is a frequently used food dye (registered as E160d) and it is homologated in the USA, Australia, New Zealand, and the EU. It is well known that lycopene plays a major part in the prevention or treatment of functional problems such are: cardiovascular diseases, various forms of cancer (breast, stomach, prostate, skin, cervical, lung, ovarian, pancreatic), alopecia, cataracts, asthma, infertility, arterial hypertension, hypercholesterolemia, inflammations, and degenerative diseases (diabetes, atherosclerosis, osteoporosis) as well as muscular degenerations caused by age (Cronin, 2000; RaO \& RaO, 2007; Khan et al., 2008).

Due to the scientific interest, researchers in various fields find more uses for lycopene every year. Nowadays lycopene is thoroughly studied from the microbiological, nutritional, and medical point of view, by complex techniques and procedures, in which the essential step is the extraction method. The progress of technology has tremendous impact on the diversification of extraction methods, evolving - in a relatively short amount of time - from traditional extraction methods with various solvents, to complex methods based on high performance liquid chromatography techniques (HPLC), enzymatic techniques, or even supercritical fluid techniques.

The present research focuses on lycopene extraction from various tomato types, fresh or processed, using classical extraction methods. The obtained results were analysed using principal component analysis and the best extraction procedure was chosen.

\section{Materials and methods}

\subsection{Materials}

The biological material used in the study was under 4 distinct forms: fresh tomatoes, dried tomatoes in a Stericell drying chamber (BMT, USA), at $70^{\circ} \mathrm{C}$ temperature, for 2 hours, up to a constant mass, lyophilised tomatoes for 48 hours in a Christ Alpha 1-4 Plus lyophilisation device (Fisher Bioblock Scientific GmbH, Belgium), and preserved tomatoes as tomato paste and juice.

\subsection{Extraction}

The following extraction solvents were added to the vegetable material: chloroform: methanol=2:1 (v:v), hexane:acetone=1:1 (v:v), calcium bicarbonate:methanol=2 g/100 ml, ethyl alcohol 95\%, absolute methyl alcohol.

The ratio raw material:solvent was 1:10 (w/v), chosen according to the experimental study carried out by JITTAWAN and SIRITHON in 2011. The biological material was weighted 
(Mettler Toledo, USA) and after trituration it was mixed with the extraction solvent and homogenized. After $30 \mathrm{~min}$ of rest with regular stirring, the sample was filtered through filter paper and prepared for spectrophotometric determination of lycopene (JITTAWAN \& SiRitHON, 2011).

\subsection{Lycopene determination}

The lycopene was determined from the filtered solution by reading the absorbance using a UV visible spectrophotometer (JENWAY 6505 UV- VIS, UK) at $472 \mathrm{~nm}$. The lycopene content was calculated by the following formula (LALEYE et al., 2010):

$$
\text { mg of lycopene per } 100 \mathrm{~g}=\frac{3.1206 \times \text { absorbance } \times \text { volume } \times \text { dilution }}{\text { Weight of sample } \times 1000(\mathrm{~g})} \times 100
$$

\subsection{Statistical analysis}

The experimental results were analysed using Principal Component Analysis (PCA) with full cross-validation. PCA constitutes the most basic statistical method of all multivariate data analysis, and involves decomposing one "data matrix" into a structural part (model) and a "noise" part (error). The main purpose of all multivariate data analysis is to decompose the data in order to detect and model the "hidden phenomena". PCA was assessed using the Unscrambler X 10.1 software version from CAMO Software AS (Oslo, Norway). PCA was used to evaluate the experimental results for lycopene concentrations in different raw materials obtained from tomato, using different extraction methods.

\section{Results and discussion}

The main aim of the present study was to find the relations between the variables (the tomato processing type, the extraction solvent, temperature, storage duration, and light exposure) and the response (the lycopene quantity) in the data set, at the same time, through the analysis of the principal components (PCA).

In order to detect potential errors in the input of the data, the data set was graphically represented, and it was observed that the data input was accurate, as no samples were found outside the parameters under evaluation. At first, the analysis of the critical points was carried out by using the number of components deemed optimal. The system recommends a number of 6 main components, which explain 100\% the data variation, for calibration, as well as for the validation of results. A number of 4 main components may explain over $90 \%$ of the data variation, with a result validation of $78 \%$.

The samples are uniformly distributed in the graphic representation of the residual variant, indicating that there are no outliers present (i.e. no results of erroneous measurements or aberrant data). The PCA model is interpreted by the evaluation of the scores and loadings complementary graphs after the removal of the outliers, if they exist.

Figure 1 shows that the PC-1 (principal component 1) axis is given by the variation of the extracted lycopene quantity, but also by the influence of the solvent, thus explaining $39 \%$ of the data variation. The factors taken into consideration as a response were the extinction read on the spectrophotometer and the lycopene concentration calculated on its basis. As the two variables are dependent on each other, they appear as a single point on the loadings graph. 

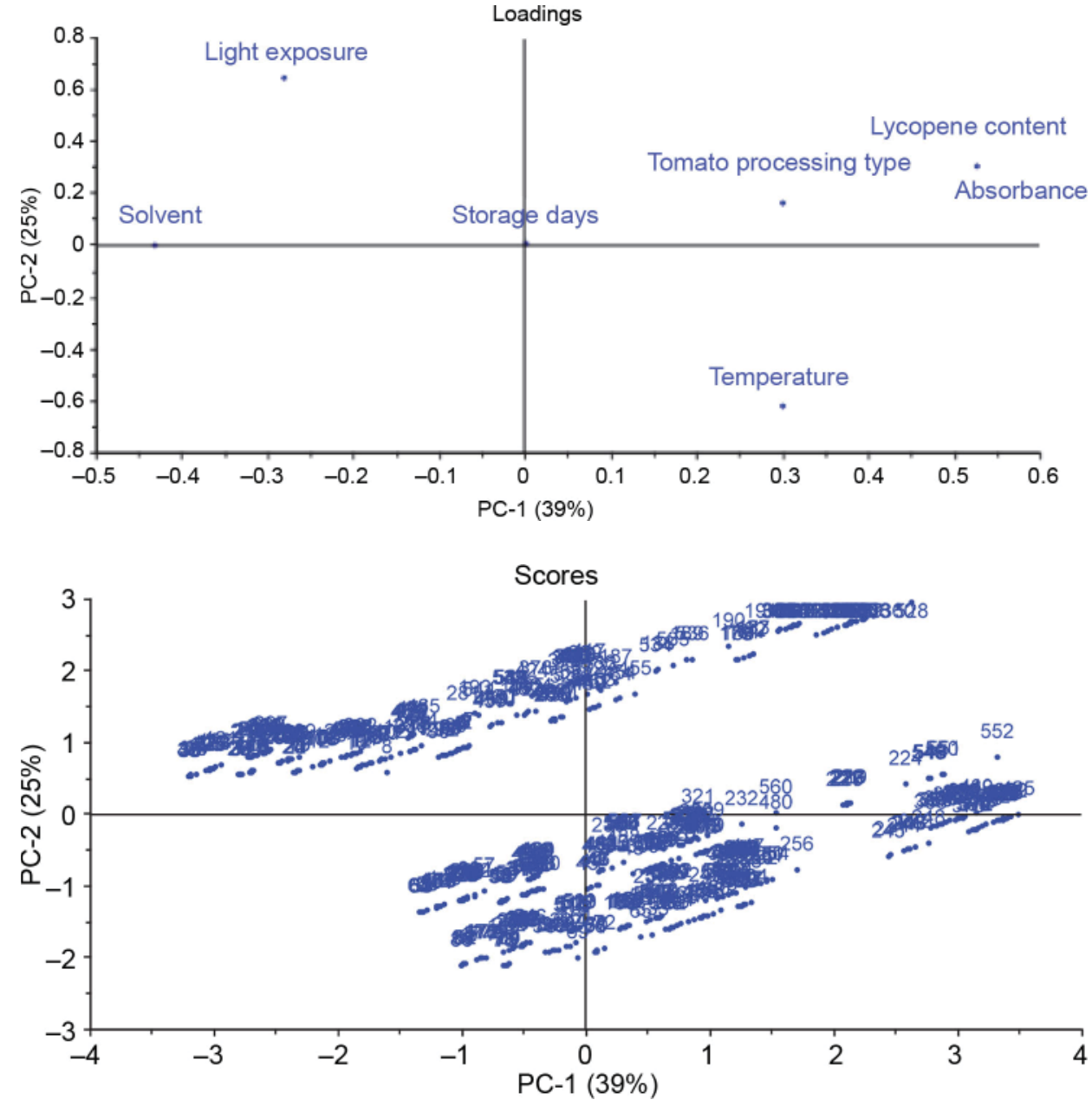

Fig. 1. The scores and loadings plots for the first two principal components

Similarly, it was seen that the solvent influences the quantity of lycopene extracted from tomatoes as follows: the largest amount of lycopene was extracted when the extraction was performed by means of chloroform:methanol (between $4.4 \mathrm{mg} / 100 \mathrm{~g}$ and $11.9 \mathrm{mg} / 100 \mathrm{~g}$ ), followed by hexane:acetone (between $1.4 \mathrm{mg} / 100 \mathrm{~g}$ and $5.8 \mathrm{mg} / 100 \mathrm{~g}$ ), and ethanol 95\% (between $1.2 \mathrm{mg} / 100 \mathrm{~g}$ and $5.6 \mathrm{mg} / 100 \mathrm{~g}$ ) (Fig. 2). RANVEER and co-workers (2013) observed that the extraction of lycopene with a mixture of solvents (like hexane:acetone or chloroform: methanol) had the highest lycopene content among all other extractions carried out with individual solvents. 


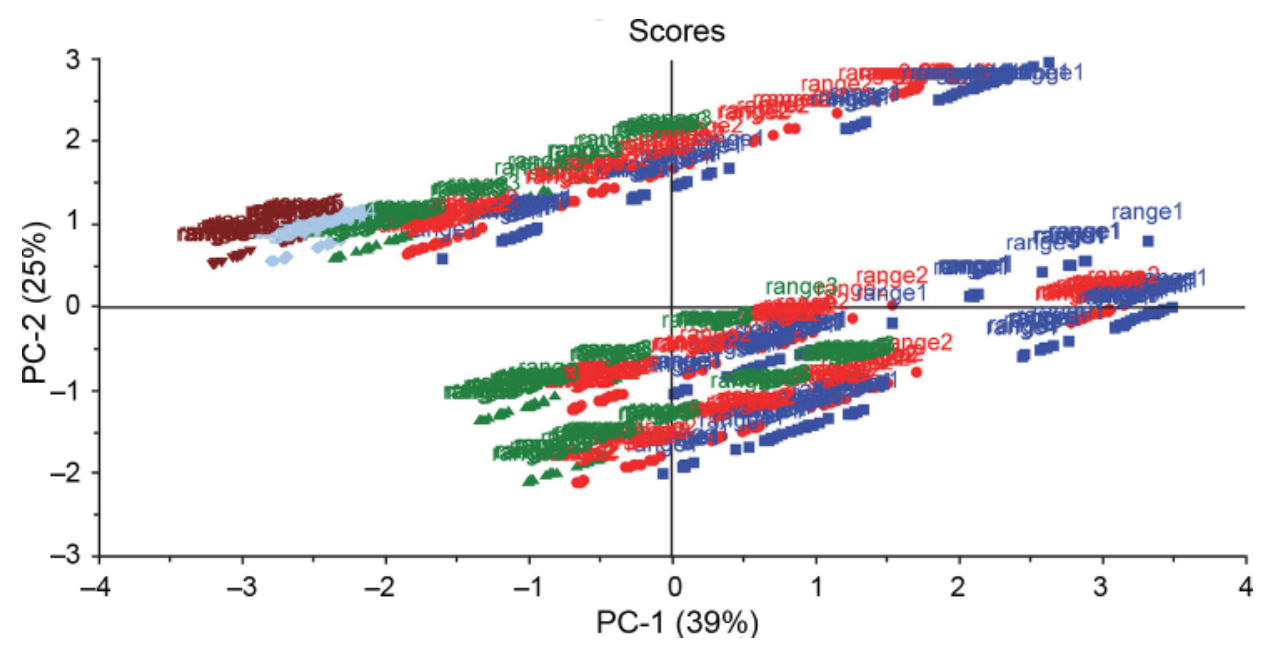

Fig. 2. The scores graph for the first 2 principal components with sample grouping according to the solvent used (range 1, blue: chloroform:methanol; range 2, red: hexane:acetone; range 3, green: ethanol 95\%; range 4, light blue: methanol; range 5, garnet: methanol with $\left.\mathrm{Ca}\left(\mathrm{HCO}_{3}\right)_{2}\right)$

PC-2, accounting for $25 \%$ of the data variation, is mainly given by the exposure to light during the storage, and to a smaller extent by the maintenance temperature of the lycopene samples. Figure 3 shows that a higher storage temperature favours the concentration of the extracted lycopene. The results are in accordance with those obtained by Ен and ТЕон (2012), who used ultrasonic assisted extraction of lycopene from tomatoes and found an optimum temperature for extraction of $47.6^{\circ} \mathrm{C}$ and obtained $5.11 \mathrm{mg} \mathrm{g}^{-1}$ dry weight. Also, in the enzyme assisted lycopene extraction from tomatoes performed by ZuoRro and co-workers (2011), temperatures between $10-50{ }^{\circ} \mathrm{C}$ were studied to establish the optimum temperature for extraction of $30^{\circ} \mathrm{C}$.

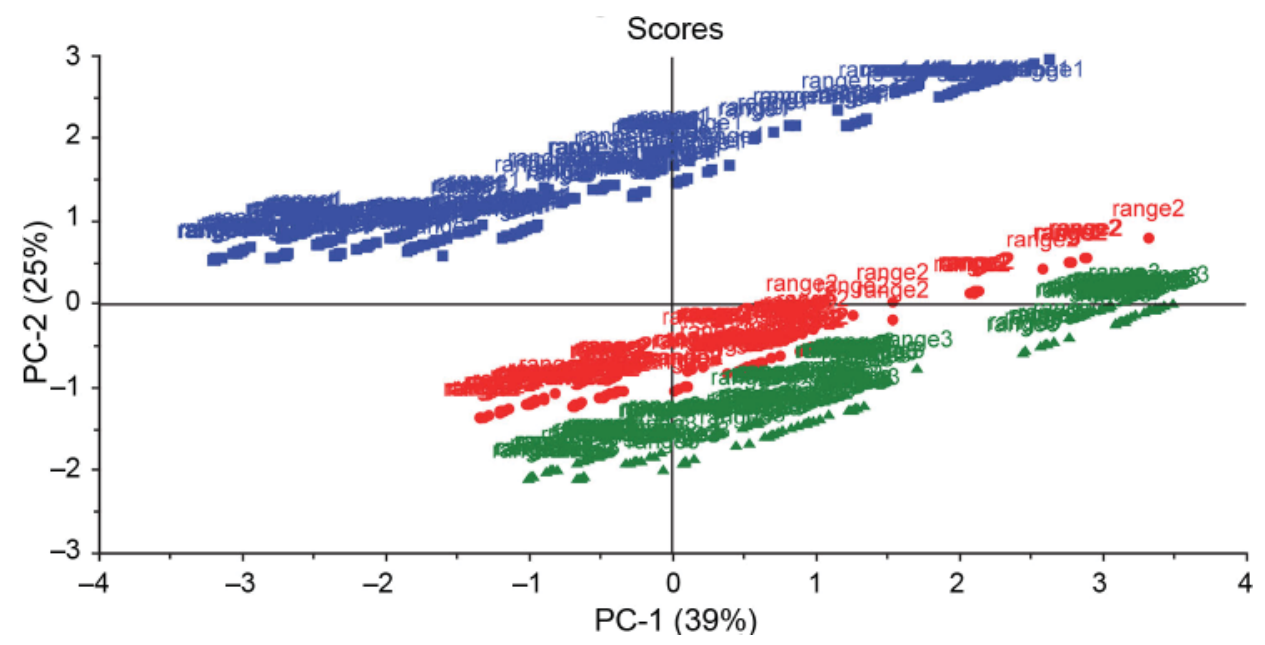

Fig. 3. The scores graph for the first $2 \mathrm{PCs}$, with sample grouping according to the storage temperature (range 1, blue: room temperature; range 2 , red: refrigeration temperature; range 3 , green: freezing temperature) 
PC-3, accounting for $14 \%$ of the data variation, is given by the storage duration of the lycopene-containing samples. Figure 4 shows that short-term storage has no great impact on the quantity of extracted lycopene, but in case the storage duration increases to 30 days, the quantity of lycopene extracted from tomatoes increases considerably when volatile solvents are used. This also might be due to the concentration of the samples due to the solvent volatility. The dry matter content increases through natural drying, the solution is less polar, and the lycopene is easily accessed.
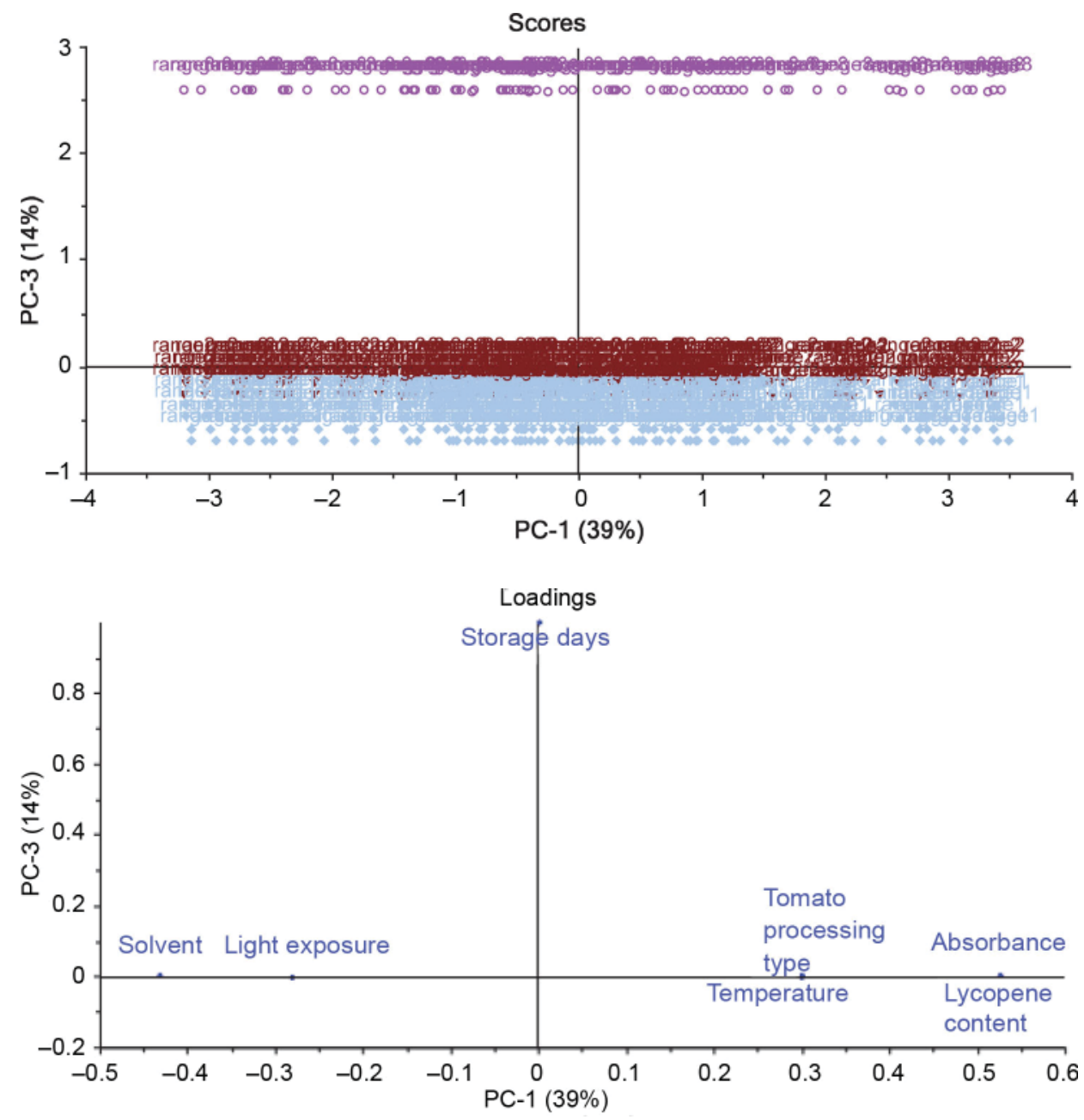

Fig. 4. The graphs of scores and loadings for PC-1 and PC-3 with sample grouping according to storage duration

PC-4, accounting for $12 \%$ of the data variation, is given by the variation of the type of biological material used for lycopene extraction. Figure 5 shows that the lyophilised tomatoes (range 8 - dark grey) contain a higher amount of lycopene $(14.11 \mathrm{mg} / 100 \mathrm{~g})$ compared to fresh tomatoes (range 1 - blue in online version, $4.13 \mathrm{mg} / 100 \mathrm{~g}$ ). Also, $11.38 \mathrm{mg} / 100 \mathrm{~g}$ lycopene was obtained from tomato juice and $6.01 \mathrm{mg} / 100 \mathrm{~g}$ from dried tomatoes. 

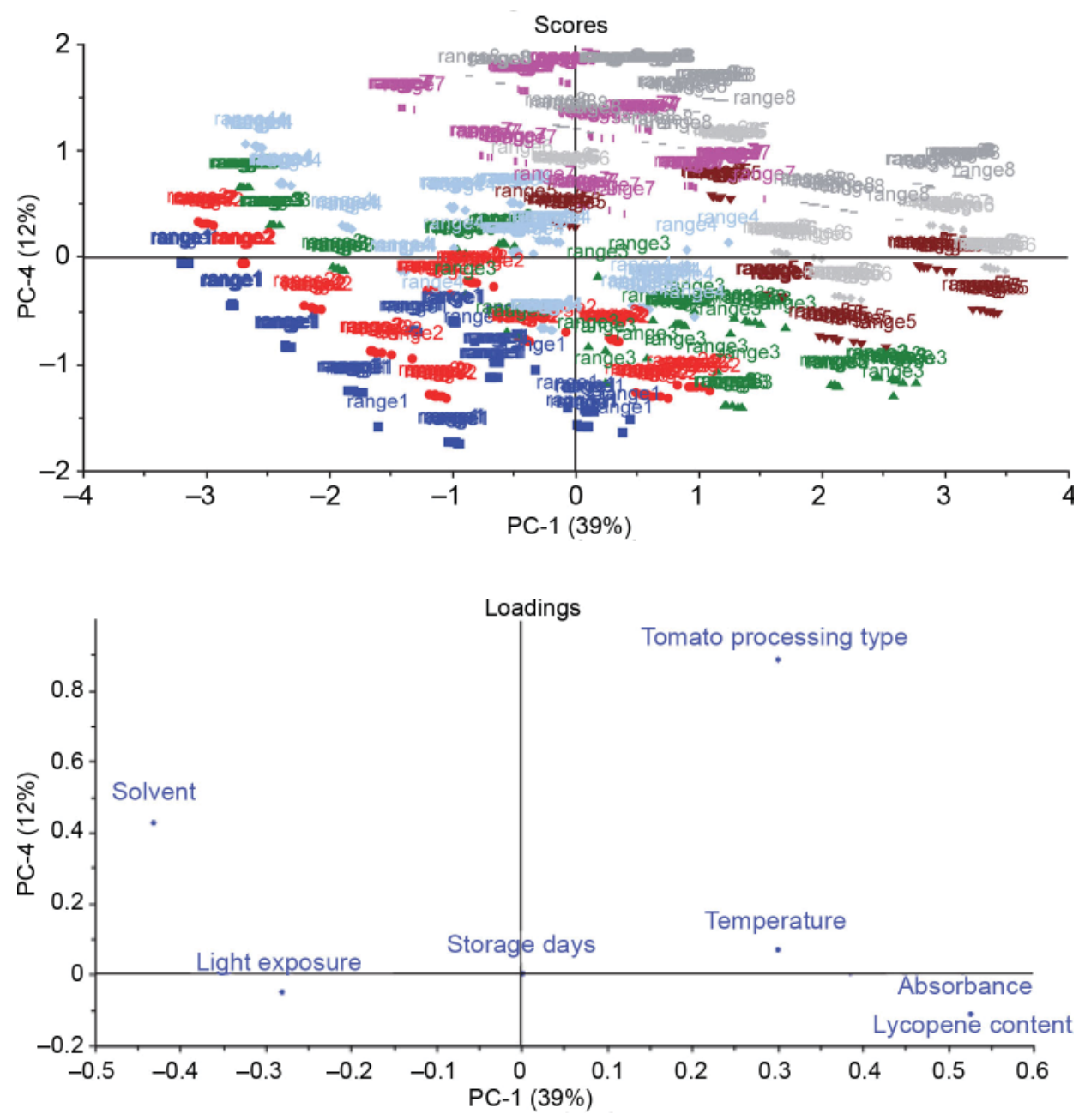

Fig. 5. The graphs of scores and loadings for PC-1 and PC-4 with sample grouping according to the tomato type used (range 1, blue: Turkish tomatoes; range 2, red: tomato paste (broth); range 3, green: dried Turkish tomatoes; range 4, light blue: Romanian cherry tomatoes; range 5, garnet: dried cherry tomatoes; range 6 , light grey: tomato juice; range 7 , pink: lyophilised cherry tomatoes; range 8 , dark grey: lyophilised Turkish tomatoes)

The obtained results are comparable with those obtained by TAVARES and RODRIGUEZAMAYA (1994), who found a mean composition of lycopene in tomatoes of $31.1 \mu \mathrm{g} \mathrm{g}^{-1}$. They also analysed different tomato products and found $12-73 \mu \mathrm{g}$ lycopene/g in fresh tomatoes, 53-68 $\mu \mathrm{g} \mathrm{g}^{-1}$ in tomato juice, $56-273 \mu \mathrm{g} \mathrm{g}^{-1}$ in puree, $110-240 \mu \mathrm{g} \mathrm{g}^{-1}$ in tomato paste, and 59-143 $\mu \mathrm{g} \mathrm{g}^{-1}$ in ketchup. The lycopene concentration is dependent on the tomato cultivar also, as shown by MARTínEZ-VALVERDE and co-workers (2002), who analysed nine commercial cultivars of tomato produced in Spain and found lycopene concentrations between 18.6 and $64.98 \mathrm{mg} \mathrm{kg}^{-1}$. 
The light exposure did not have a notable influence on lycopene extraction from tomatoes.

Lycopene concentrations between 0.106 and $15.89 \mathrm{mg} / 100 \mathrm{~g}$ were obtained in the present study. RANVEER and co-workers (2013) studied the lycopene extraction from tomatoes and found the highest lycopene concentration in tomato peel $\left(376.17 \mu \mathrm{g} \mathrm{g}^{-1}\right)$ and the lowest concentration in tomato pulp $\left(47.6 \mu \mathrm{g} \mathrm{g}^{-1}\right)$. MACHMUDAH and co-workers (2012) obtained 0.82 $\mathrm{mg}$ lycopene $\mathrm{g}^{-1}$ dry matter from tomato peels using chloroform Soxhlet extraction. ZuORRO and co-workers (2011) obtained a medium concentration of lycopene in tomato peels of 342 $\mathrm{mg} / 100 \mathrm{~g}$ dry matter using hexane extraction. Also, their study demonstrated an 8-18-fold increase in the extraction yield by the use of enzyme preparation (pectinase and cellulose) (ZuORRo et al., 2011).

\section{Conclusions}

Lycopene extraction from various tomato products, using different parameters was performed and the obtained results were analysed using principal component analysis. The lycopene extraction was favoured when dried and processed biological material was used, compared to fresh tomatoes. Also, the solvent used in the extraction procedure had a great impact: the chloroform:methanol solvent had a positive effect on lycopene extraction from tomato products. Lycopene extraction is also influenced by the temperature, the higher the extraction temperature, the higher the lycopene concentration.

\section{References}

Aguilar, F., Autrup, H., Barlow, S., Castle, L., Crebelli, R., Dekant, W., Engel, K.H., Gontard, N., Gott, D., Grilli, S., Gürtler, R., Larsen, J.C., Leclercq, C., Leblanc, J.C., Malcata, F.X., Mennes, W., Milana, M.R., Pratt, I., Rietjens, I., TobBack, P. \& Toldrá, F. (2008): Use of lycopene as a food colour, scientific opinion of the panel on food additives, flavourings, processing aids and materials in contact with food. EFSA Journal, $674,1-66$.

Boileau, T.W., Boileau, A.C. \& Erdman, J.W. (2002): Bioavailability of all-trans and cis-isomers of lycopene. Exp. Biol. Med., 227, 914-919.

Chasse, G.A., Mak, M.L., Deretey, E., Farkas, I., Torday, L.L., Papp, J.G., Sarma, D.S.R., Agarwal, A., Chakravarthi, S., Agarwal, S. \& Rao, A.V. (2001): An ab initio computational study on selected lycopene isomers. J. Mol. Struc.-THEOCHEM, 571(1), 27-37.

Cronin, J.R. (2000): Lycopene: The powerful antioxidant that makes tomatoes red. J. Altern. Complem. Med., 6, 92-94.

Eh, A.L.S. \& Teoh, S.G. (2012): Novel modified ultrasonication technique for the extraction of lycopene from tomatoes. Ultrason. Sonochem., 19(1), 151-159.

Grossman, A.R., Lohr, M. \& Im, C.S. (2004): Chlamydomonas reinhardtii in the landscape of pigments. Anne. Rev. Genet., 38, 119-173.

Ishida, B.K., Turner, C., Chapman, M.H. \& McKeon, T.A. (2004): Fatty acids and carotenoid composition in gac (Momordica cochinchinensis Spreng.) fruit. J. Agr. Food Chem., 52, 274-279.

Jittawan, K. \& Sirithon, S. (2011): Phytochemicals and antioxidant activity of different fruit fractions (peel, pulp, aril and seed) of Thai gac (Momordica cochinchinensis Spreng.). Food Chem., 127(3), 1138-1145.

Khan, N., Afaq, F. \& Mukhtar, H. (2008): Cancer chemoprevention through dietary antioxidants: progress and promise. Antioxid. Redox Sign., 10, 475-510.

Laleye, L.C., Al Hammadi, S.I., Jobe, B. \& Rao, M.V. (2010): Assessment of lycopene content of fresh tomatoes (Lycopersicon esculentum Mill.) and tomato products in the United Arab Emirates. J. Food Agric. Environ., 8(3-4), 142-147. 
Machmudah, S., Winardi, Z.S., Sasaki, M., Gotoa, M., Kusumotod, N. \& Hayakawad, K. (2012): Lycopene extraction from tomato peel by-product containing tomato seed using supercritical carbon dioxid. J. Food Eng., 108(2), 290-296.

Martínez-Valverde, I., Periago, M.J., Provan, G. \& Chesson, A. (2002): Phenolic compounds, lycopene and antioxidant activity in commercial varieties of tomato (Lycopersicum esculentum). J. Sci. Food Agr., 82(3), 323-330.

Ranveer, R.C., Patil, S.N. \& Sahoo, A.K. (2013): Effect of different parameters on enzyme-assisted extraction of lycopene from tomato processing waste. Food Bioprod. Process., 91(4), 370-375.

Rao, A.V. \& Rao, L.G. (2007): Carotenoids and human health. Pharmacol. Res., 55(3), 207-216.

Tavares, C.A. \& Rodriguez-Amaya, D.B. (1994): Carotenoid composition of Brazilian tomatoes and tomato products. LWT - Food Sci. Technol., 27(3), 219-224.

Zuorro, A., Fidaleo, M. \& Lavecchia, R. (2011): Enzyme-assisted extraction of lycopene from tomato processing waste. Enzyme Microb. Tech., 49(6-7), 567-573. 